\title{
Uma nova Rauia (Rutaceae) da Amazônia Brasileira.
}

\author{
William ANTônio RodRigues(") \\ MARLENE Freitas dA Silva(*)
}

Com a descrição abaixo de Rauia prancei W. Rodrigues \& M. F. Silva, 3 espécies do gênero são até agora conhecidas apenas para a América do Sul. As 2 outras antes descritas eram $R$. resinifera Nees et Mart. e R. ule? Krause.

Rauia prancei W. Rodr. M.F. Silva, n. sp. (Fig. 1)

Árvore pequena de $7 \mathrm{~m}$ de altura po: $10 \mathrm{~cm}$ de diâmetro, ramos glabros, densamente glandulosos. Fôlhas membranáceas, glabras, lanceoladas, brilhantes na face superio:, na in ferior pálidas com pontuações glandulíferas escuras, de $12-14 \mathrm{~cm}$ (raro até $18 \mathrm{~cm}$ ) de comprimento, por 5,5-7 (8) $\mathrm{cm}$ de largura, ápicf agudo, acuminado, base cuneada, margem in teira, revoluta. Pecíolos glabros, de $2,5-3 \mathrm{~cm}$. de comprimento por $1,5 \mathrm{~mm}$ de espessura: nervuras mediana e secundárias impresso-reticuladas de ambos os lados. Inflorescência terminal corimbosa, de $13-15 \mathrm{~cm}$ de compri. mento, ráquis longitudinalmente estriado, ramificação dicotômica ferrugínea. Botões flo ríferos longos, cilíndricos, de prefloração im. bricada, de $15 \mathrm{~mm}$ de comprimento. Cálice campanulado, de $3-4 \mathrm{~mm}$ de comprimento, densamente escamoso, internamente glabro, 5-lobado; lacínias de $0,5 \mathrm{~mm}$ de comprimento, ápice agudo. Flôres gamopétalas externa a internamente puberulentas, até $2,5 \mathrm{~cm}$ de com. primento; tubo de $7,5-10 \mathrm{~mm}$ de comprimento, pétalas 5, brancas, lineares, alternissépalas, de margem ligeiramente crenulada. Es tames 7 ( 2 férteis), de $7,5 \mathrm{~mm}$ de comprimento, com anteras oblongas de $3-4 \mathrm{~mm}$ de comprimento, de deiscência rimosa e ápice obtuso; estaminódios maiores 3 , filiformes, livres $3-4 \mathrm{~mm}$ menores do que as pétalas; 2 soldados às pétalas até $2 / 3$ de seu comprimento total Ovário globoso profundamente 5-lobado, 5-1o. cular, envolvido por um disco membranoso de
$2 \mathrm{~mm}$ de altura, irregularmente laciniado. Estilete cilíndrico, filiforme, de $2-3 \mathrm{~mm}$ de comprimento, com pêlos híspidos em tôda a sua extensão; estígma glabro, claviforme. Fruto desconhecido.

Typus: Tree $7 \mathrm{~m} \times 10 \mathrm{~cm}$ diameter. Corola white. Forest on terra firme. Brasil, Territo $\mathrm{y}$ of Rondonia, basin of rio Madeira vicinity of S. Lourenço mines, 65ㅇ 6'W; 9’ 33'S. G.T. Prance, W.A. Roärigues, J.F. Ramos \& L.G. Farias 8944. Nov. 27,1968 (Holotypus INPA 25743, Isotypus MG 39624, NY).

Esta nova espécie parece mais relacionada com $R$. resinifera Nees et Mart., da qua! distingue-se por apresentar 2 pétalas com estaminódios soldados até $2 / 3$ do seu comprimento total e 3 estaminódios livres, bem como também pela forma da antera, disco e estígma.

A espécie é assim denominada em homenagem ao Dr. Ghillean Prance, do New York Botanical Garden, que, por sua extensa e valiosa coleta. na região amazônica, vem dando grandes contribuições, para o melhor conhecimento de nossa flora.

\section{S U M M A R Y}

In this paper one new species of Rutaceae : Rauia prancei is described with one accompaning drawing. This species is distinct from the other by presenting 2 petals with staminodes connected until $2 / 3$ in total lenght and 3 free staminodes and also by anther, disc and stigma shape.

\section{BIBLIOGRAFIA CONSULTADA}

COWAN, R. S.

1967 - Rutaceae of the Guyana Highland, Mem. N. Y. Bot. Gard. 14 (3) : 1-14

ENGLER, A.

1872-77 - Rutaceae. In Martius, Fl. Bras. 12 (2) : 78196, tab. 14-40.

Krause, $\mathrm{K}$.

1914 - Rutaceae. In Pilger, R. Plantae Uleanae novae vel minus cognitae. Notizbl. Bot. Gart., Berlin $55(6): 145$.

(*) - Pesquisadores em Botânica do Instituto Nacicnal de Pesquisas da Amazônia. Bolsistas do Conselho Nacional de Pesquisas. 

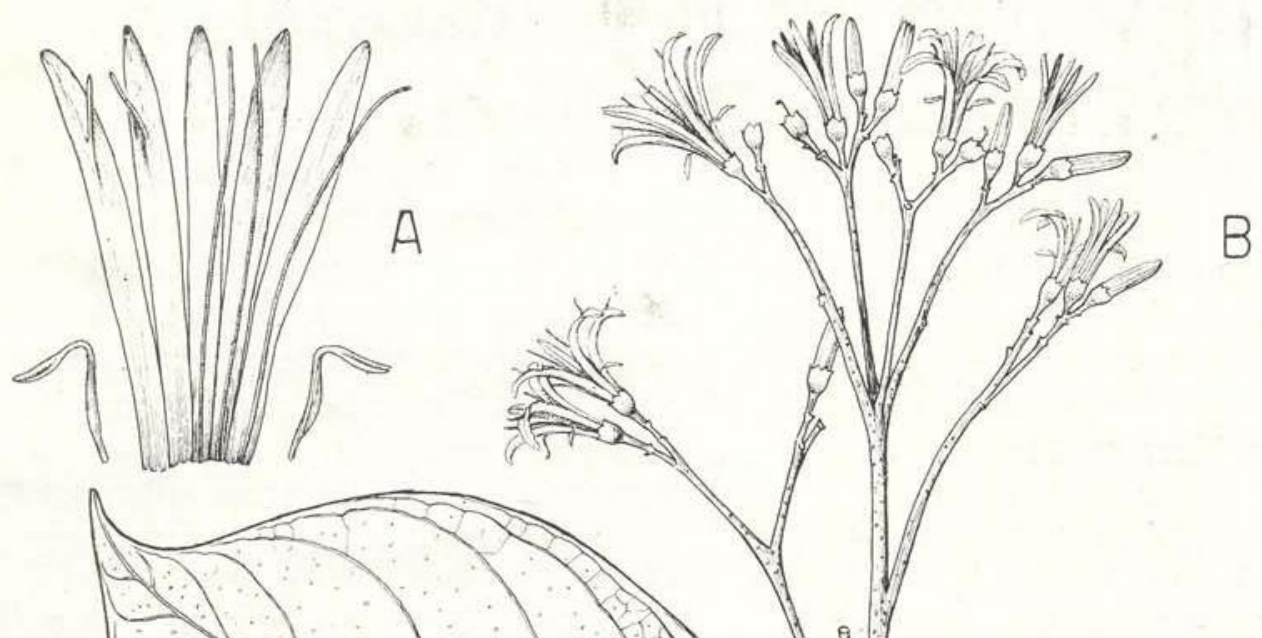

1
2
3
-5

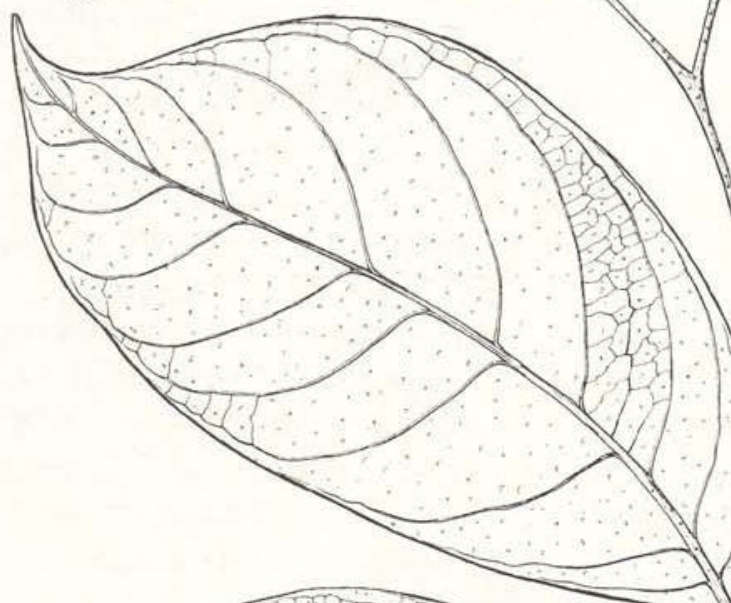

$\mathrm{cm}$
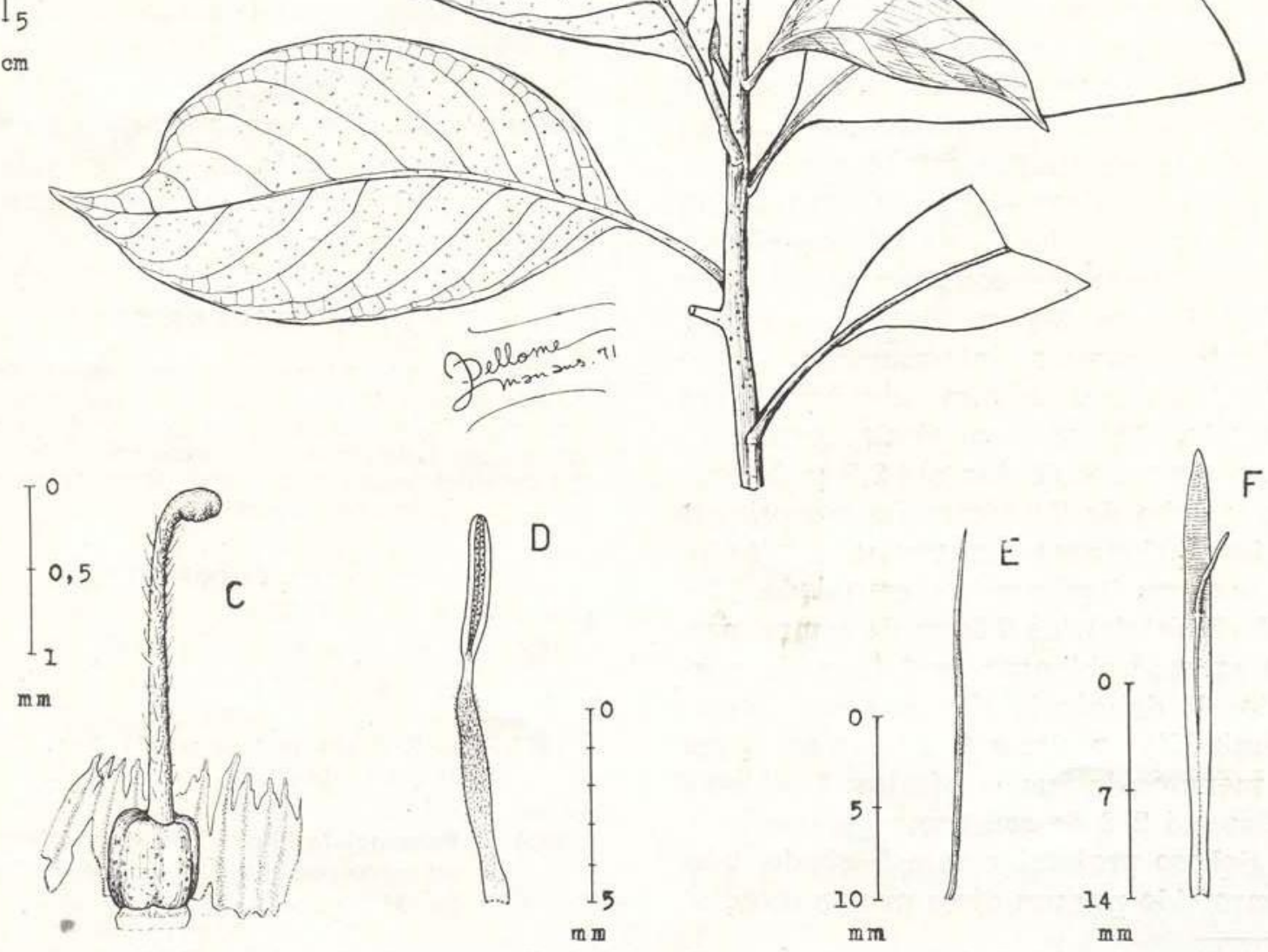

Fig. 1 - Rauia prancei. W. Rodr. \& M. F. Silva. A-Corola aberta mostrando os estames e estaminódios. $B-$ Hábito de um raminho florífero. $C$ - Pistilo e disco laciniado. $D$ - Estame fértil. E- Estaminódio filiforme. $F$ - Uma pétala com estaminódio parcialmente soldado. 